\title{
Spinohypothalamic Tract Neurons in the Cervical Enlargement of Rats: Descending Axons in the Ipsilateral Brain
}

\author{
Xijing Zhang, Ewa Kostarczyk, and Glenn J. Giesler, Jr. \\ Department of Cell Biology and Neuroanatomy, University of Minnesota, Minneapolis, Minnesota 55455
}

Spinohypothalamic tract (SHT) cells are spinal cord neurons with axons that project directly to or through the contralateral hypothalamus. Frequently, SHT axons decussate in the posterior optic chiasm, turn posteriorly and descend to unknown locations in the ipsilateral brain. We attempted to determine the course and the termination of these descending axons. Sixty neurons in the cervical enlargement of rats were antidromically activated initially from the contralateral hypothalamus and then from multiple anteriorposterior levels in the ipsilateral brain. Fifty-three (88\%) were backfired with low currents at increased latencies from the ipsilateral brain. The axons of 35 neurons were surrounded with electrode penetrations from which high currents could not activate the neuron antidromically, suggesting the examined axons terminated in the surrounded areas. Seven SHT axons that were surrounded $(20 \%)$ appeared to terminate in the contralateral hypothalamus, 5 $(14 \%)$ in the ipsilateral hypothalamus, and $9(26 \%)$ in the ipsilateral thalamus. Fourteen SHT axons (40\%) ended in the ipsilateral midbrain mainly in the superior colliculus, cuneiform nucleus or nucleus brachium inferior colliculus. An additional 11 axons were followed even farther posteriorly into the ventral pons or rostral medulla. Each of the 26 neurons that could be physiologically classified responded either preferentially or specifically to noxious mechanical stimuli. These results indicate that SHT axons course through a surprisingly long and complex path. After decussating in the hypothalamus, the axons of many SHT neurons descend Into the ipsllateral posterior thalamus, midbrain, pons, or even rostral medulla. These axons may provide nociceptive information to a variety of nuclei throughout the diencephalon and brainstem bilaterally.

[Key words: spinohypothalamic tract, axonal projection, supraoptic decussation, antidromic activation, nociception, cervical enlargement, rat]

The hypothalamus is likely to be importantly involved in autonomic, neuroendocrine and affective responses to noxious stimuli (reviewed in Janig, 1990; Giesler et al., 1994). It has generally been assumed that nociceptive information reaches the hypothalamus only through indirect, multisynaptic pathways.

\footnotetext{
Received July 13, 1995; revised Aug. 22, 1995; accepted Aug. 28, 1995.

We thank Drs. R. Elde, K. Kajander, and M. Wessendorf for critical comments on the manuscript; H. Truong for technical assistance; and $G$. Sedgewick for photography. This work was supported by NIH Grant NS25932.

Correspondence should be addressed to Glenn J. Giesler, Jr., Department of Cell Biology and Neuruanatony, 4-135 Jackson Hall, University of Minnesula, Minneapolis, MN 55455

Copyright (C) 1995 Society for Neuroscience $0270-6474 / 95 / 158393-15 \$ 05.00 / 0$
}

One such pathway has recently been described (Bester et al., 1995). However, more than 40 years ago, Chang and Ruch (1949) and Morin et al. (1951) reported that lesions in the upper cervical white matter of monkeys caused degeneration of axons in the ipsilateral hypothalamus, suggesting that nociceptive information may also reach the hypothalamus through a direct projection from the spinal cord. Chang and Ruch (1949) noted that the degenerating axons were concentrated in the supraoptic decussation (SoD), a small area of white matter medially adjacent to the optic tract. The axons were followed as they ascended to the rostral hypothalamus where they crossed the midline at the level of the posterior optic chiasm (Gudden's commissure), turned caudally, and descended in the SoD on the opposite side. The axons were followed posteriorly to the region immediately ventral to the medial geniculate where they disappeared. During the three decades that followed these studies, several reports have also noted degenerating axons in the hypothalamus following spinal lesions in several species (reviewed in Burstein et al., 1990a). Nonetheless, until recently, the possible existence of a direct projection from the spinal cord to the hypothalamus has received little attention.

In the last several years, the spinohypothalamic tract (SHT) has been examined using modern anatomical and electrophysiological methods. In rats, injections of retrograde tracers restricted to the hypothalamus labeled as many as 9000 neurons bilaterally throughout the length of the spinal cord. This number is similar to the total number of spinothalamic tract neurons in all spinal segments in rats (Burstein et al., 1990b). Labeled SHT neurons were located primarily in the marginal zone, deep dorsal horn, and the area around the central canal (Burstein et al., 1987, 1990a; Carstens et al., 1990; Menetrey and DePommery, 1991), areas that are each involved in processing nociceptive information (Willis, 1985). Injections of the anterograde tracer PHA-L into the spinal cord of rats labeled axons in several areas of the hypothalamus including the lateral, posterior and dorsal hypothalamus. In addition, many labéled fibers were seen in the SoD bilaterally and crossing the midline within the posterior optic chiasm (Cliffer et al., 1991). Recently, Newman et al. (1995) reported that injections of biotin-dextran into the spinal cords of squirrel monkeys anterogradely labeled axons and terminals in many of the same regions of the hypothalamus.

SHT neurons have been physiologically examined at several levels of the spinal cord (Burstein et al., 1987, 1991; Katter et al., 1992; Dado et al., 1994a-c). The overwhelming majority of SHT neurons responded strongly to noxious mechanical stimuli. Many were also powerfully activated by noxious thermal stimuli (Burstein et al., 1987, 1991; Dado et al., 1994b). In these studies, the projections of SHT axons were also examined. The axons 

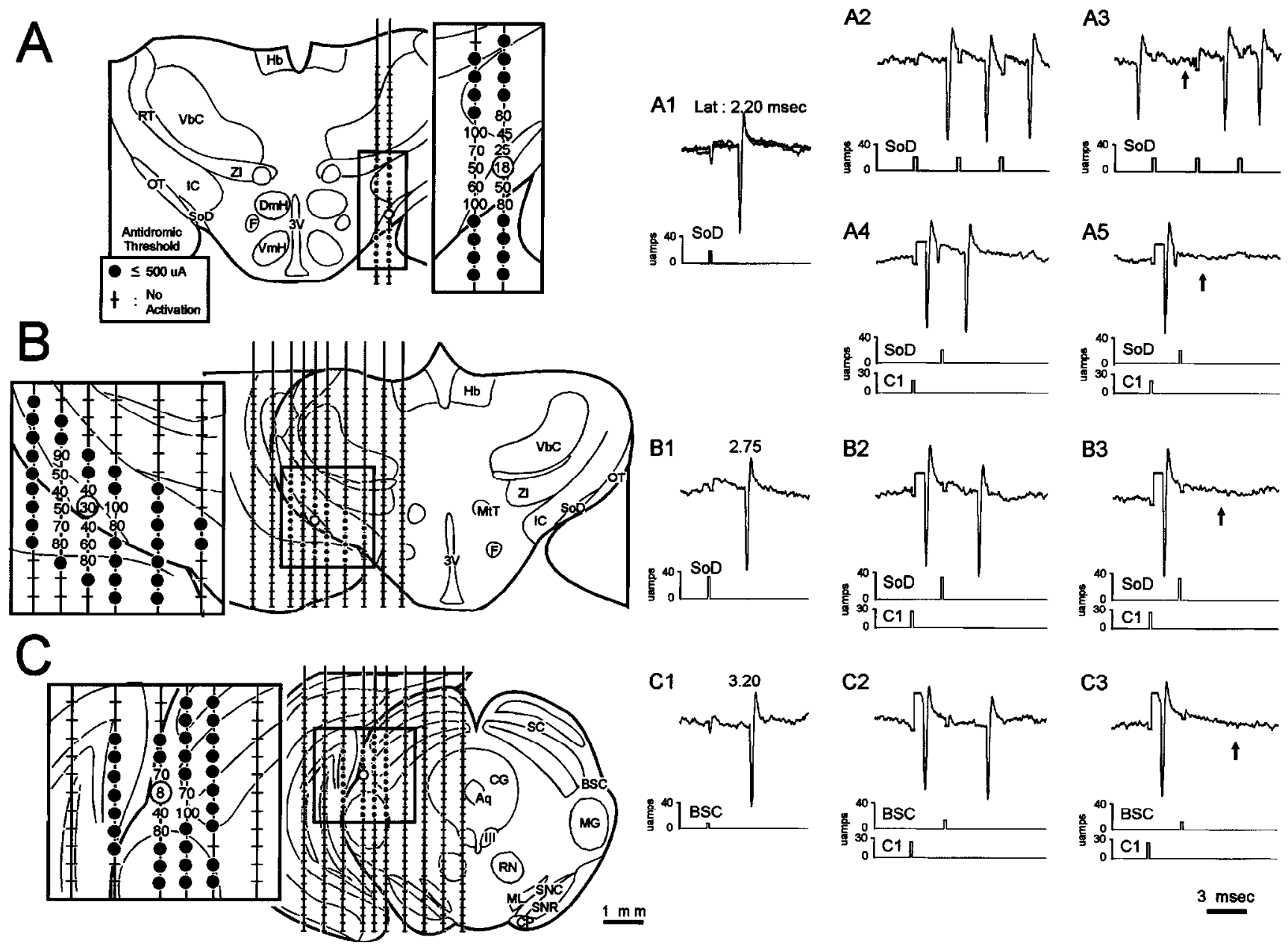

Figure 1. Methods for antidromic activation of an SHT neuron from the contralateral hypothalamus and ipsilateral brain. Electrode penetrations were made in the contralateral hypothalamus $(A)$, and in the ipsilateral thalamus $(B)$ and midbrain $(C)$. The amplitude of current required to activate the neuron antidromically is indicated in each box and inset. Low threshold points are circled. The initial low threshold point was located in the contralateral hypothalamus. The putative antidromic response had a stable latency (three overlapping traces in $A I$ ), followed high frequency ( 333 $\mathrm{Hz}$ ) trains of pulses $(A 2)$ and collided with orthodromic action potentials $(A 3)$. The neuron was also antidromically activated from a low threshold point in the upper cervical cord (A4). When the interval between stimuli delivered in the hypothalamus and cord was reduced collision occurred (A5). This demonstrates that action potentials elicited from both points traveled in the same axon. The neuron was also antidromically activated from the ipsilateral SoD $(B)$ and brachium of the superior colliculus $(C)$. Antidromic responses from both of these locations also collided with antidromic responses from the upper cervical cord $(B 2-B 3, C 2-C 3)$, indicating that action potentials elicited at these levels also traveled in the same axon. Arrows indicate the points at which the antidromic action potentials elicited from the brain would have occurred. Note that the antidromic latency increased as the axon apparently descended from the hypothalamus to the midbrain. The amplitude of several stimulus artifacts have been reduced for clarity. See Appendix for abbreviations.

were antidromically activated at progressively longer latencies initially in the SoD of the contralateral hypothalamus, and then in posterior optic chiasm near the midline and in the ipsilateral hypothalamus. In several cases, the examined axons were also antidromically activated in the ipsilateral thalamus. In two cases, descending SHT axons were followed posteriorly into the rostral ipsilateral midbrain (Dado et al., 1994a). The purpose of the present study was to examine the descending portion of these axons in detail. Specifically, we attempted to determine (1) the path of descending SHT axons, (2) the nuclei that receive afferent input from this projection, and (3) how far caudally these axons project.

\section{Materials and Methods}

The methods used in the present study were similar to those reported previously (Burstein ct al., 1991; Dado et al., 1994a). Bricfly, rats (400$750 \mathrm{gm}$ ) were treated with atropine, anesthetized with urethane, artificially ventilated, and paralyzed with gallamine triethiodide. End-tidal
$\mathrm{CO}_{2}$ and core temperature were monitored and maintained at normal levels. Mannitol was injected (i.v.) to reduce edema. The dorsal surfaces of the upper cervical spinal cord, the cervical enlargement and the brain were exposed bilaterally. The sinuses on the surface of the brain were tied and removed to allow unimpeded penetration of the brain by a stimulating electrode. In several cases, the cerebellum was removed using aspiration to expose the dorsal surface of the pons and medulla.

Single units within segments C6-C8 were recorded using stainless steel microelectrodes (5-10 M $)$ ). Current pulses (cathodal, $200 \mu \mathrm{sec}$, $500 \mu \mathrm{A})$ were delivered through a monopolar stainless steel stimulating electrode in the contralateral hypothalamus. After isolating an antidromically activated action potential (criteria for antidromicity in Fig. $1 \mathrm{Al}-$ A3), the stimulating electrode was moved systematically through the hypothalamus until a point was located at which the antidromic threshold was $\leq 30 \mu \mathrm{A}$. Such points are referred to as low threshold points. A unit was classified as an SHT neuron only if it could be antidromically activated using currents $\leq 30 \mu \mathrm{A}$ from a site within the hypothalamus. Antidromically elicited action potentials were amplified, filtered, sent to a computer, digitized and stored for subsequent analysis. It was possible to measure antidromic latencies reliably to the nearest 0.05 msec. 
After confirming that a neuron projected to the hypothalamus, a second stimulating electrode was inserted into the cervical cord white matter ( $\mathrm{C} 1$ segment) contralateral to the recording site. This stimulating electrode was moved systematically until the examined neuron was antidromically activated from $\mathrm{Cl}$ with currents $\leq 30 \mu \mathrm{A}$. Collision of action potentials evoked from the electrodes in the hypothalamus and cervical cord was demonstrated (Fig. 1A4-A5). This procedure was used to verify that antidromic spikes elicited from both sites traveled in the same axon.

To determine whether the axon of the examined SHT neuron crossed the midline, the stimulating electrode in the brain was moved to the diencephalon ipsilateral to recording site and a series of electrode penetrations were made across the mediolateral extent of the brain at several anterior-posterior levels (Fig. 1B). If the neuron could not be antidromically activated in the ipsilateral diencephalon, the stimulating electrode was returned to the contralateral hypothalamus and attempts were made to surround the initial low threshold point with electrode penetrations in which the axon could not be activated antidromically with current pulse up to $500 \mu \mathrm{A}$. If the neuron was antidromically activated in the ipsilateral diencephalon, attempts were made to follow the projection of its axon using antidromic stimulation at multiple anterior-posterior levels in the ipsilateral diencephalon and brainstem (see Fig. $1 B, C$ ). Within a given anterior-posterior plane, tracks were separated by 300 or $500 \mu \mathrm{m}$ mediolaterally. Within each track the electrode was advanced from the dorsal to the ventral surface and antidromic thresholds were determined at $200 \mu \mathrm{m}$ intervals. Action potentials evoked at each low threshold point were collided with those from the cervical cord (Fig. 1B2-B3,C2-C3). To help insure accurate histological reconstruction of low threshold points, anterior-posterior planes of stimulation tracks were separated by at least $500 \mu \mathrm{m}$.

To locate the apparent terminal areas of SHT axons, we attempted to surround penetrations containing the most posterior low threshold point posteriorly, medially, and laterally with penetrations in which the axon could not be activated antidromically with up to $500 \mu \mathrm{A}$. Current pulses of $500 \mu \mathrm{A}$ spread from 600 to as far as $1600 \mu \mathrm{m}$ (Ranck, 1975; Burstein et al., 1991; Dado et al., 1994a). Stimulating tracks were separated by $\leq 500 \mu \mathrm{m}$. Therefore, we interpret the failure of $500 \mathrm{uA}$ pulses to activate axons antidromically from these penetrations that surround a low threshold point as evidence that the axon did not pass through the stimulated areas.

In several cases, two or more low threshold points with different antidromic latencies were found at the same anterior-posterior level. In many of these cases, the axon could also be followed posteriorly to low threshold points with longer latencies. At levels having multiple antidromic latencies, the point with the shortest latency was thought to indicate the location of the parent axon activated in passage. The longest latency points were taken as indications of the position of the termination of collatcral branches from the parcnt axon if they (1) had latencies that were longer than those found 1-2 mm caudally and (2) were surrounded laterally or medially by tracks in which $500 \mu \mathrm{A}$ pulses did not antidromically activate the neuron.

Cutaneous receptive fields and response characteristics of recorded cells were determined using innocuous and noxious mechanical stimuli. Units were classified as low-threshold (LT), wide-dynamic-range (WDR) and high-threshold (HT) neurons according to their responses to mechanical stimulation of their receptive fields (see Dado et al., 1994b, for details).

At the end of each experiment, electrolytic lesions ( $25 \mu \mathrm{A}$ for $10-40$ sec) were made at the tip of the stimulating electrode at each of low threshold points in the brain and spinal cord and at the tip of the recording electrode. Rats were perfused with $0.9 \%$ saline followed by $10 \%$ formalin containing $1 \%$ potassium ferrocyanide (Prussian blue reaction). The distances between the recording site in the spinal cord and the initial low threshold point in the hypothalamus were measured. Three and one-half millimeters was added to this measurement to reflect the distance between the recording site and the contralateral lateral funiculus (Dado et al., 1994c). Distances between low threshold points in the ipsilateral brain were calculated as the shortest distance between the two points. The areas of the brain and spinal cord containing lesions were cut transversely at $50 \mu \mathrm{m}$ and stained with neutral red. The locations of lesions were reconstructed with the aid of a drawing tube attached to a microscope. The atlas of Paxinos and Watson (1986) was used to help identify the locations of lesions within the brain. In 10 cases in which two low threshold points were separated by $\leq 600 \mathrm{~mm}$, a lesion at only one low threshold point was made. The location of the other point was reconstructed stereotaxi- cally. Recording sites in the spinal cord were assigned to one of three areas (Burstein et al., 1990a): superficial dorsal horn (SDH), deep dorsal horn $(\mathrm{DDH})$, or ventral horn $(\mathrm{VH})$.

\section{Results}

An example of antidromic activation of a spinal neuron from the contralateral hypothalamus and ipsilateral thalamus and midbrain is illustrated in Figure 1. Within the first track in the contralateral hypothalamus, the lowest antidromic threshold was $50 \mu \mathrm{A}$. The electrode was removed and reinserted $300 \mu \mathrm{m}$ lateral to the first track. The lowest antidromic threshold in the second track was $18 \mu \mathrm{A}$, in a position immediately lateral to the lowest threshold point in the first track. The antidromic latency was $2.2 \mathrm{msec}$. This point was located at the dorsal border of the $\mathrm{SoD}$ in the lateral hypothalamus (Fig. 1A). Antidromic action potentials elicited from this and all other low threshold points for this and other neurons occurred at a constant latency $(A l)$, followed high-frequency stimulation $(A 2)$, collided with orthodromic action potentials (A3) and with antidromic action potential elicited using a second stimulating electrode in the upper cervical cord (A4-A5).

After the confirming that the unit was antidromically activated from the contralateral hypothalamus, the stimulation electrode was moved to ipsilateral brain. The neuron in Figure 1 was also antidromically activated from the ipsilateral thalamus and midbrain (Fig. $1 B, C$ ). At each level, a single lowest threshold point was surrounded dorsally, ventrally, laterally, and medially by points at which higher currents were required for antidromic activation. The lesions at the low threshold points were located in SoD in the lateral thalamus (Fig. $1 B$ ) and in the brachium of the superior colliculus in the midbrain (Fig. $1 C$ ). The antidromic latency from the site in the ipsilateral thalamus was 2.75 minec, and in the ipsilateral midbrain was $3.20 \mathrm{msec}$ (Fig. 1 $\mathrm{Al}-\mathrm{Cl}$ ). Note that the antidromic latency was shortest in the contralateral hypothalamus and increased as the axon apparently descended into the ipsilateral thalamus and midbrain.

\section{Recording sites}

Examples of lesions at recording sites in the DDH and the SDH are shown in Figure 2, $A$ and $B$. The locations of recording sites of 58 SHT neurons are illustrated in Figure 3. Two lesions were not recovered. Nine (16\%) neurons were recorded in the SDH, $48(83 \%)$ were in the $\mathrm{DDH}$, and 1 was in the $\mathrm{VH}$. One recording site was located in segment $\mathrm{C} 6,45$ were in $\mathrm{C} 7,11$ were in $\mathrm{C} 8$, and 1 was at the border of $\mathrm{C} 6$ and $\mathrm{C} 7$.

\section{Physiological characterization}

Twenty-six SHT neurons were physiologically characterized. Fifteen (58\%) neurons were classified WDR (Fig. 5) and 11 (42\%) HT (Figs. 6, 7). Two WDR neurons were recorded in the $\mathrm{SDH}$. Twelve were recorded in the DDH. One lesion at a recording point of a WDR neuron was not recovered. Ten HT neurons were recorded in the DDH and one was recorded in the VH. WDR neurons were mainly concentrated in the middle of DDH and HT neurons were recorded mainly in the lateral part of the DDH (Fig. 3).

All 26 SHT neurons had excitatory receptive fields on the ipsilateral forepaw or forelimb. Most (23) cutaneous receptive fields typically involved areas of one to five toes or small parts of the forepaw. In one case, the receptive field covered nearly the entire ipsilateral forelimb. The receptive fields of two neurons extended onto the shoulder and chest, and one neuron had a receptive field that was discontinuous. 

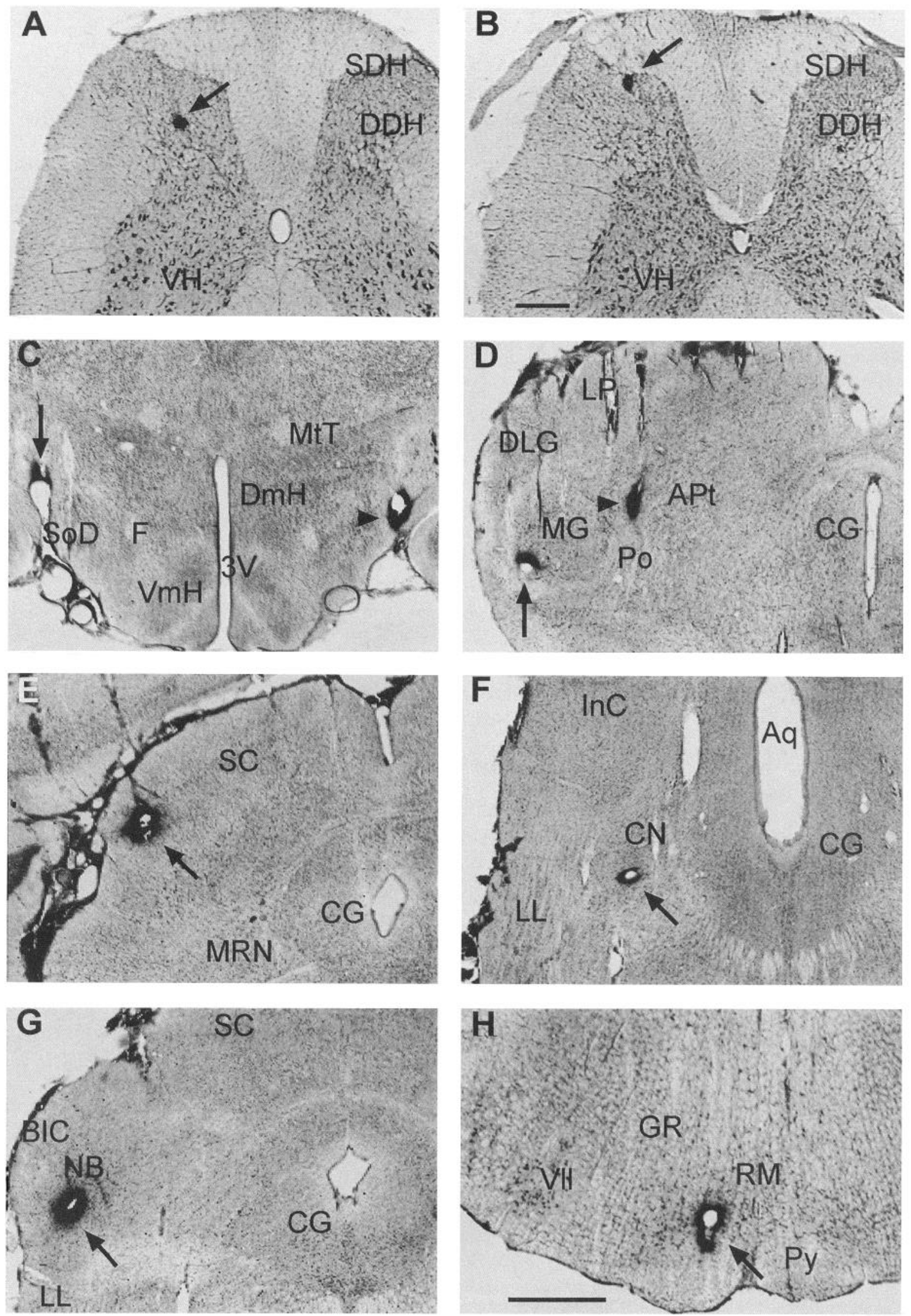


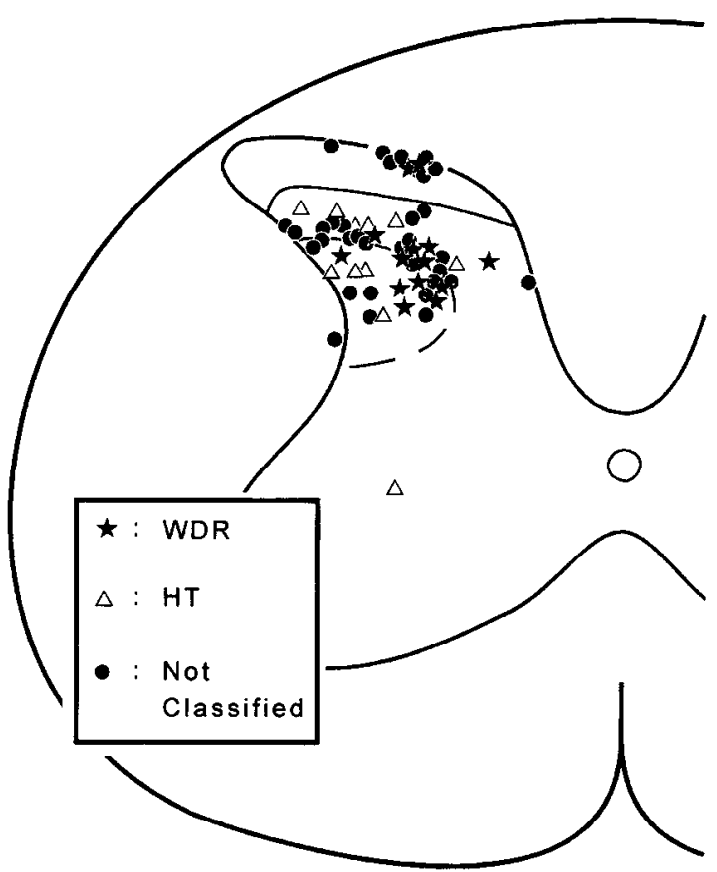

Figure 3. Locations of recording sites of 58 SHT neurons in the ccrvical enlargement. Forty-eight $(83 \%)$ were in the deep dorsal horn $(\mathrm{DDH})$, nine $(16 \%)$ were in the superficial dorsal horn $(\mathrm{SDH})$, and one was in the ventral horn (VH). Fourteen of the neurons for which the recording site was determined were classified as WDR and 11 as HT neurons.

\section{Neurons antidromically activated from the contralateral} hypothalamus

The 60 examined neurons were activated initially with high currents in the contralateral hypothalamus. Fifty-six lesions marking the initial low threshold points were located in the contralateral hypothalamus. The remaining four were in the ipsilateral hypothalamus. The threshold currents for antidromically activating these neurons from these points ranged from 4 to $30 \mu \mathrm{A}(15.7$ $\pm 1.0 \mu \mathrm{A}$, mean $\pm \mathrm{SE}$ ). The majority of the low threshold points were in the SoD. Others were in the optic tract, posterior part of optic chiasm and lateral hypothalamus. No difference in locations was apparent between low-threshold points from which neurons in the SDH and DDH were antidromically activated. A photomicrograph of a lesion at an initial low threshold point in the contralateral hypothalamus is shown in Figure $2 \mathrm{C}$.

For 35 SHT axons, we were able to surround the apparent end of the axon with tracks in which the axon could not be activated with pulses of up to $500 \mu \mathrm{A}$. In seven of these cases $(20 \%)$, the axons of recordcd SHT ncurons werc surrounded in the contralateral hypothalamus. These 7 points were in the SoD (3), the internal capsule near SoD (2) or in the optic tract (2). Each of the seven SHT neurons was recorded in the DDH. Responses to innocuous and noxious mechanical stimulation were determined for three of these neurons. One was classified as WDR and two as HT neurons.

\section{Descending SHT axons}

Fifty-three SHT neurons (88\%) were also antidromically activated from 206 low threshold points in the ipsilateral brain. In all cases, the antidromic latency at each point in the ipsilateral brain was longer than the latency from the initial point in the contralateral hypothalamus.

Ipsilateral hypothalamus. Fifty-eight low threshold points were found for antidromic activation of 35 SHT neurons in this area. These points were concentrated medially within the caudal part of the ipsilateral optic chiasm (Fig. $4,-1.3 \mathrm{~mm}$ from bregma) or laterally within or near the SoD and optic tract (Fig. 4, -1.3 through -3.6 from bregma). One low threshold point was located in the ventromedial hypothalamic nucleus. A photomicrograph of a lesion at a low threshold point in the ipsilateral hypothalamus is shown in Figure $2 C$.

Five $(14 \%)$ of 35 axons were surrounded with ineffective stimulating tracks in the ipsilateral hypothalamus. Surrounded low threshold points in the ipsilateral hypothalamus were found in the SoD (2), optic tract (2) and the posterior part of optic chiasm (1) (Fig. 4, -1.3 through -3.6 ). The recording sites for these five neurons were all in the DDH. Two such neurons were physiologically characterized and both were classified as HT neurons.

Ipsilateral thalamus. Sixty-six low threshold points for antidromic activation of 31 SHT neurons were found in this area. These low threshold points were located within or near SoD, optic tract, the medial geniculate, the brachium superior colliculus, the posterior thalamic nucleus, and the ventrobasal complex (Fig. 4, -3.6 through -6.0 ). A photomicrograph of lesions of the two low threshold points in the ipsilateral thalamus is shown in Figure $2 D$.

The axons of $9(26 \%)$ neurons were surrounded with ineffective stimulating tracks in the ipsilateral thalamus, The points from from which these axons were activated were in the SoD (3), optic tract (3), the brachium superior colliculus (1), dorsal part of medial geniculate (1), and the ventrobasal complex (1) (Fig. 4, -4.3 through -6.0 ). The recording sites for 7 of these 9 neurons were in the DDH (4), SDH (3); 2 sites were not recovered. Two of the 9 units were physiologically characterized; both were classified as WDR neurons.

Ipsilateral midbrain. Sixty-one low threshold points for antidromic activation of 28 descending SHT axons were located in the midbrain, including two in the contralateral midbrain. Fortythree low threshold points were located in the midbrain tegmentum, including the nucleus of the brachium of the inferior colliculus, the cuneiform nucleus, lateral part of the mesencephalic reticular nucleus and caudally in or close to the lateral lemniscus (Fig. 4, -6.0 through -8.7 ). Eighteen low threshold points were located in the tectum, mainly in the intermediate and deep layers of the superior colliculus (Fig. 4, -6.0 through -7.0 ).

Fourteen SHT axons $(40 \%)$ were surrounded in the ipsilateral midbrain. These surrounded low threshold points were located in the superior colliculus, cuneiform nucleus, the nucleus of the brachium of the inferior colliculus, lateral lemniscus, and the

$\leftarrow$

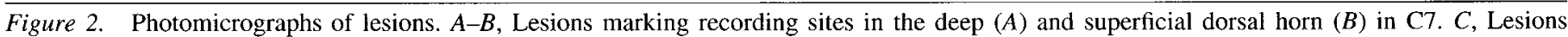
marking low threshold points for antidromic activation in the contralateral (arrowhead) and ipsilateral (arrow) hypothalamus. $D-H$, Low threshold

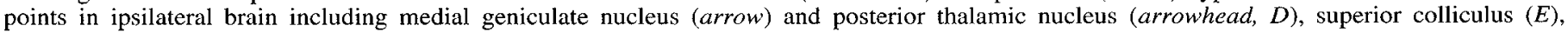

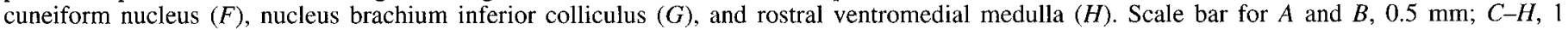
mm. See Appendix for abbreviations. 
inferior colliculus (Fig. 4, -6.0 through -8.7 ). Figure 5 illustrates an example of an SHT neuron with an axon that appeared to terminate in the ipsilateral superior colliculus (SC). The antidromic latency from the initial low threshold point was 2.5 msec ( $\mathrm{a}$ in Fig. $5 A, E, F$ ). As the axon descended in the ipsilateral thalamus and midbrain, low threshold points were located progressively more medial and dorsal. The latencies increased (from $3.2 \mathrm{msec}$ to $4.05 \mathrm{msec}$ ) as the axon was followed posteriorly. Points $b$ and $c$ were in the SoD in the lateral part of the ipsilateral thalamus (Fig. 5E), $\mathrm{d}$ and e were in the brachium superior colliculus and $f$ and $g$ were in the intermediate layers of the SC (Fig. 5E). The axon of this neuron appeared to project to or through the contralateral hypothalamus, cross the midline and descend through the ipsilateral hypothalamus and thalamus. It then appeared to pass through the brachium superior colliculus and terminate in the ipsilateral SC. The neuron was recorded in the DDH of $\mathrm{C} 7$ (Fig. 5B) and was classified as a WDR neuron (Fig. 5D). A photomicrograph of the lesion at $\mathrm{f}$ is shown in the Figure $2 E$. Four axons in this study appeared to terminate in the ipsilateral SC. One additional axon appeared to pass through the ipsilateral SC, cross the midline in the posterior part of the commissure of the SC and enter the contralateral SC (Fig. 4, -6.0 , -7.0 ). The recording points for these five neurons were in the DDH (2), and SDH (3). Both tested neurons were classified as WDR neurons.

The cuneiform nucleus (CN) appeared to be another site in which SHT axons terminate in the ipsilateral midbrain. Figure 6 illustrates an example of a neuron having an axon that ap- peared to terminate at the border of the $\mathrm{CN}$ and the central gray. The neuron was initially activated antidromically in the contralateral hypothalamus at a latency of $2.3 \mathrm{msec}$. The axon was then antidromically activated in the ipsilateral posterior optic chiasm (a) at a latency of $2.5 \mathrm{msec}$ (Fig. $6 A, E, F$ ). The neuron was antidromically activated with low currents at progressively longer latencies from $b$ through $g$ in the ipsilateral hypothalamus and thalamus (Fig. 6A). These points were located in the SoD and optic tract. As the axon traveled posteriorly in the diencephalon, it appeared to course laterally and dorsally (Fig. 6A,E). From the level of the posterior thalamus to the caudal midbrain, multiple low threshold points were seen at each examined level, suggesting the presence of several branches from the SHT axon at each level. In addition in the midbrain, the axon and its branches appeared to turn medially. In the caudal midbrain, three low threshold points were seen (Fig. 6A,E). Points o and p were separated from q by $3 \mathrm{~mm}$ in which $500 \mu \mathrm{A}$ currents could not activate the neuron antidromically, suggesting that separate branches were present in the dorsal and ventral tcgmentum. A surrounded low threshold point was found near the border of the $\mathrm{CN}$ and central gray (p). A second surrounded low threshold point $(q)$ was located near the lateral lemniscus in the ventral tegmentum (Fig. $6 E$ ). The unit was recorded in the dorsal part of the DDH in segment $\mathrm{C} 7(C)$ and was classified as an HT neuron $(D)$.

Four descending SHT axons appeared to terminate in the ipsilateral $\mathrm{CN}$ (Fig. 4, -8.7). A photomicrograph of a lesion at a surrounded low threshold point in the ipsilateral $\mathrm{CN}$ is shown

Figure 4. Summary of the locations of lesions marking 206 low threshold points for antidromic activation of 53 SHT neurons in the ipsilateral brain. The position of each symbol indicates the location of a low threshold point. The type of symbol is indicated in the inset. The surrounded low threshold points appear to represent the terminal areas of the parent axons and collateral branches. The left side of each section is ipsilateral to the recording site. Numbers indicate the posterior distance from the bregma (Paxinos and Watson, 1986). Two low threshold points from an SHT axon that appeared to cross back to the intermediate layers of the contralateral superior colliculus are indicated at right $(-7.0)$. Sec Appendix for abbreviations.

Figure 5. An example of an SHT neuron with an axon that descended to the ipsilateral superior colliculus. A, Dorsal view of the area of the brain outlined by the box in the diagram in $C$. Penetrations with a stimulating electrode were made at multiple anterior-posterior levels in the ipsilateral brain. The minimum antidromic threshold in each penetration is represented by a symbol (inset). The initial low threshold point is indicated by the letter $\mathrm{a}$ in the contralateral hypothalamus. The axon was also activated at progressively longer latencies in the ipsilateral diencephalon and midbrain as it was followed posteriorly $(b-g)$. The most caudal point in ipsilateral superior colliculus $(g)$ was surrounded ventrally, dorsally, medially, laterally, and posteriorly by tracks in which $500 \mathrm{~mA}$ currents did not activate the neuron antidromically, suggesting that the axon terminated in the surrounded area. $B$, Location of the recording site in C7. $D$, Responses of this WDR neuron to cutaneous mechanical stimulation. $E$, Locations of lesions made at low threshold points a-g. $F$, Antidromic action potentials elicited at each low threshold point. The amplitude of stimulus artifacts have been reduced for clarity. Sce Appendix for abbreviations.

Figure 6. An example of an SHT neuron with an axon that descended to the ipsilateral cuneiform nucleus. $A$, Dorsal view of the area of the brain outlined by the box in diagram $B$. The axon was activated in the ipsilateral hypothalamus and was followed posteriorly as far as the ipsilateral midbrain $(a-q)$. The most caudal points in the ipsilateral midbrain ( $\mathrm{p}$ and $\mathrm{q}$ ) were surrounded by tracks in which $500 \mathrm{~mA}$ pulses did not activate the neurons antidromically, suggesting that the axon terminated in the surrounded areas. $C$, Recording site in C7. $D$, Responses of this HT neuron to mechanical stimuli. $E$, Locations of low threshold points in five levels. Point $\mathrm{o}$ is in the cuneiform nucleus, $\mathrm{p}$ at the border of cuneiform nucleus and the central gray, and $\mathrm{q}$ is in the lateral lemniscus. $F$. Antidromic action potentials elicited from a-q. Note that in the midbrain, there are three or four low threshold points with different latencies at each examined lcvel, indicating tcrminating branches may have emanated from the parent axon. The amplitude of several stimulus artifacts have been reduced. See Appendix for abbreviations.

Figure 7. An example of an SHT neuron with an axon that descended to the ipsilateral medulla. A, Dorsal view of the area of the brain outlined by the box in the inset. The axon was antidromically activated from low threshold points in the contralateral hypothalamus and ipsilateral brainstem. $a-h$, In the medulla, many low threshold points with short latencies were noted $(i-m)$. These points appeared to represent collateral branches of the axon that had crossed from the contralateral to the ipsilateral side in the medulla. These short latency antidromic response made it impossible to determine whether the ipsilateral descending axonal branch reached this level. $B$, Recording site in $\mathrm{C} 8$. $C$, Responses of this $\mathrm{HT}$ neuron to mechanical stimuli. $D$ and $E$, Locations of low threshold points $\mathrm{a}-\mathrm{m}$ and antidromic action potentials elicited at these points. Note the progressive increases in the antidromic latencies as the axon was followed posteriorly in the ipsilateral midbrain, pons, and medulla $(b, d-h)$. Note also in the most rostral plane in the ipsilateral midbrain, two low threshold points $(b, c)$ were found $(A, D)$. Point $\mathbf{b}$ was in the mesencephalic reticular nucleus and $c$ in pontinc reticular nucleus. The latency from $c$ was longer than those at more posteriorly located points. These findings suggest that a slowly conducting daughter branch left the descending parent axon and terminated in the pontine reticular nucleus. The amplitude of several stimulus artifacts have been reduced. See Appendix for abbreviations. 


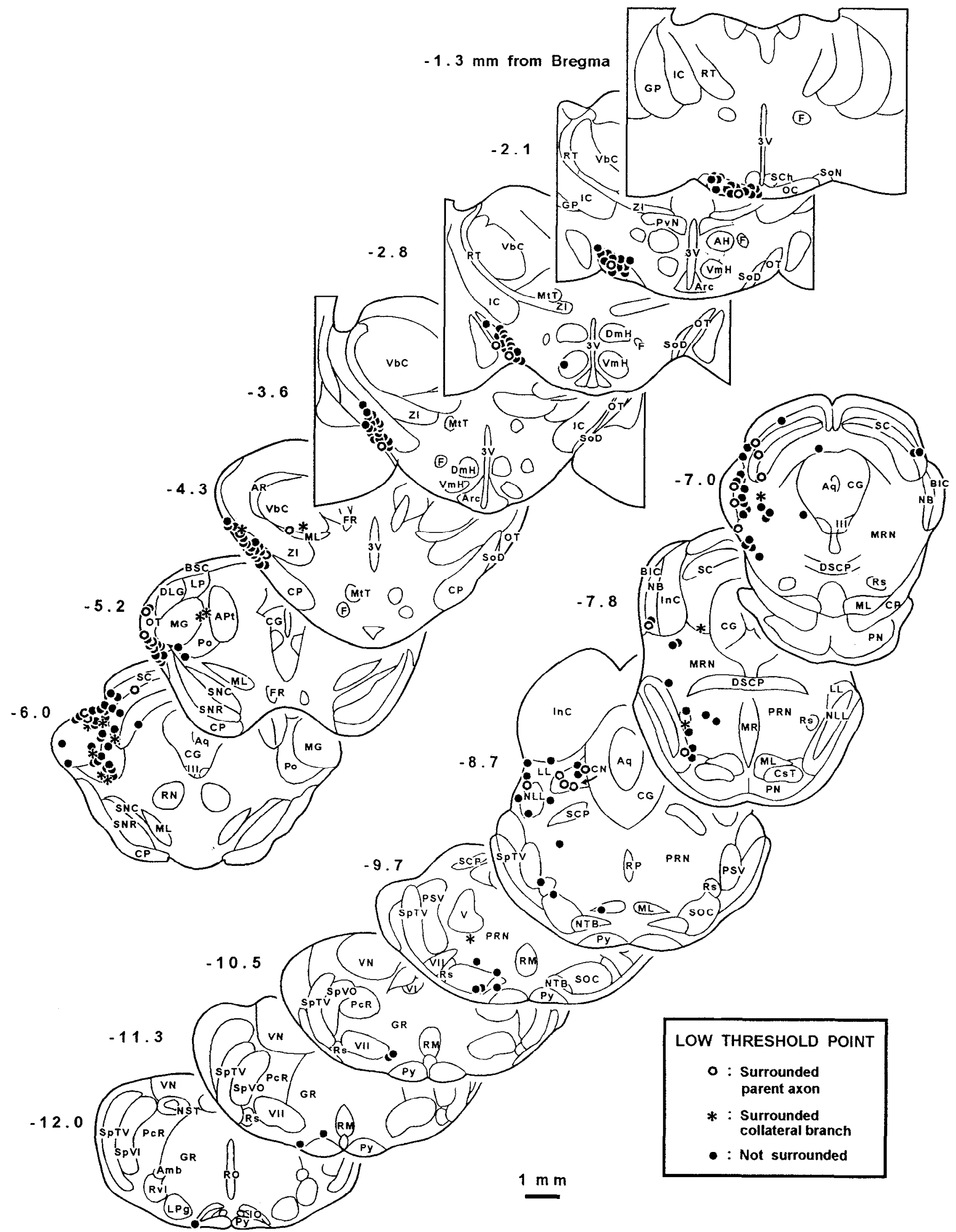

Figure 4. 
8400 Zhang et al. - Descending SHT Axons in the Ipsilateral Brain

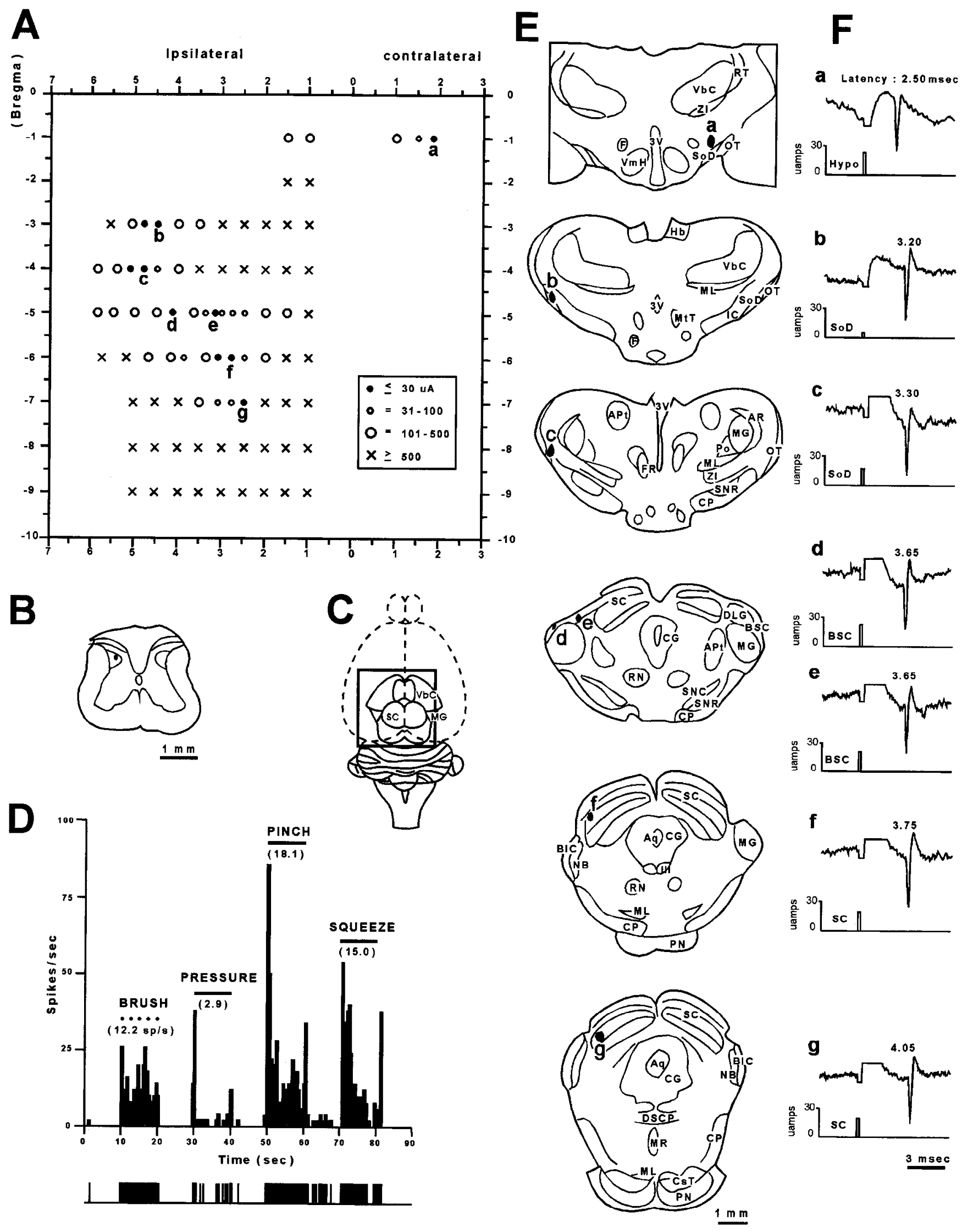

Figure 5 . 
$\Delta$

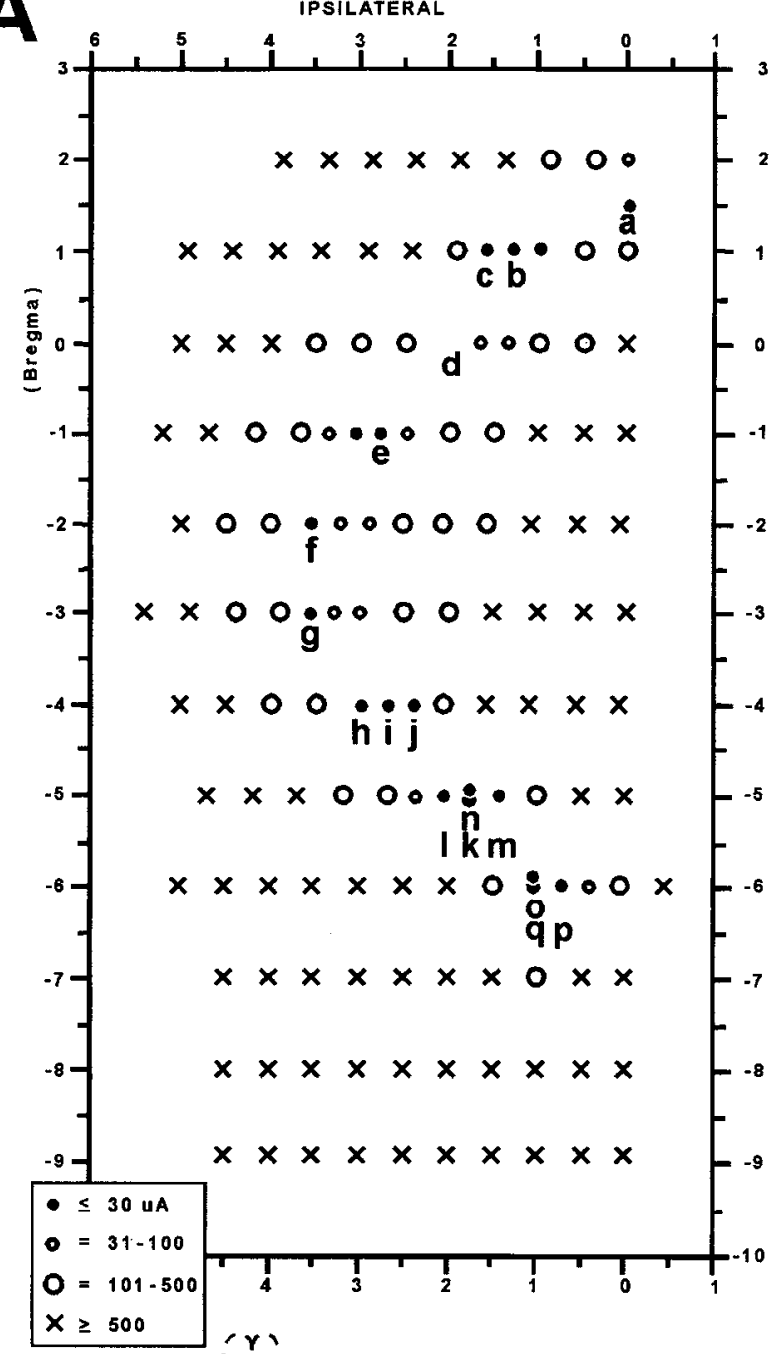

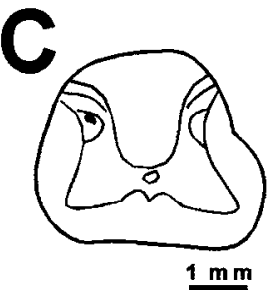
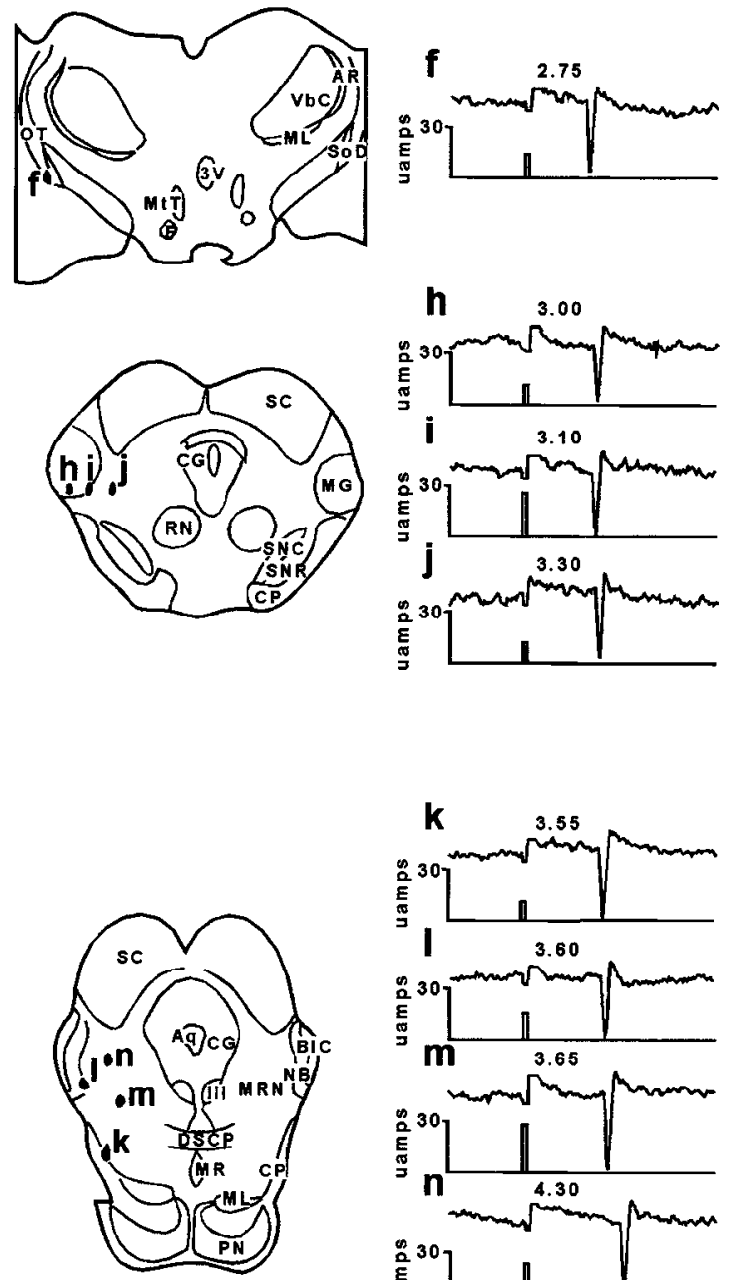

D
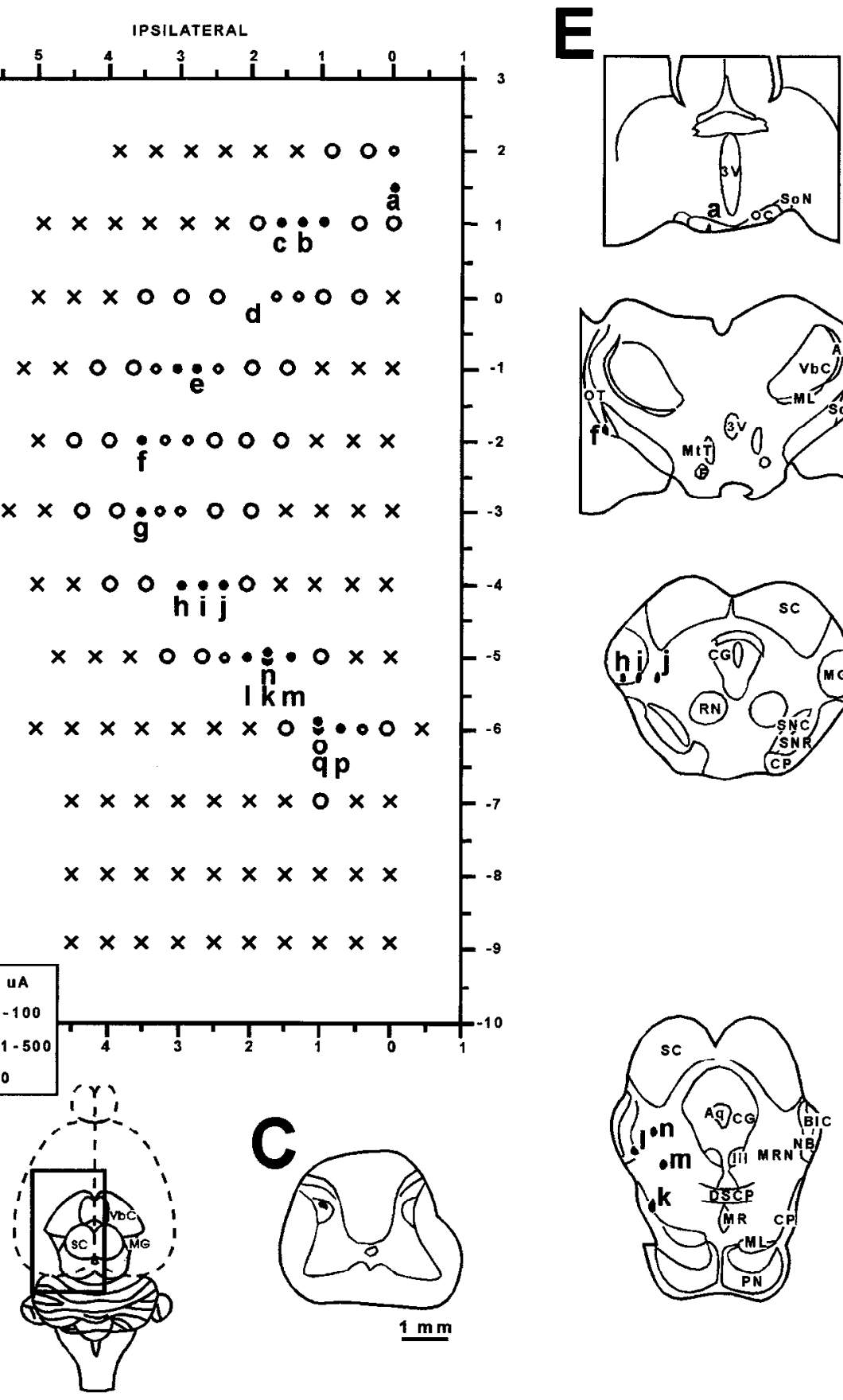

5
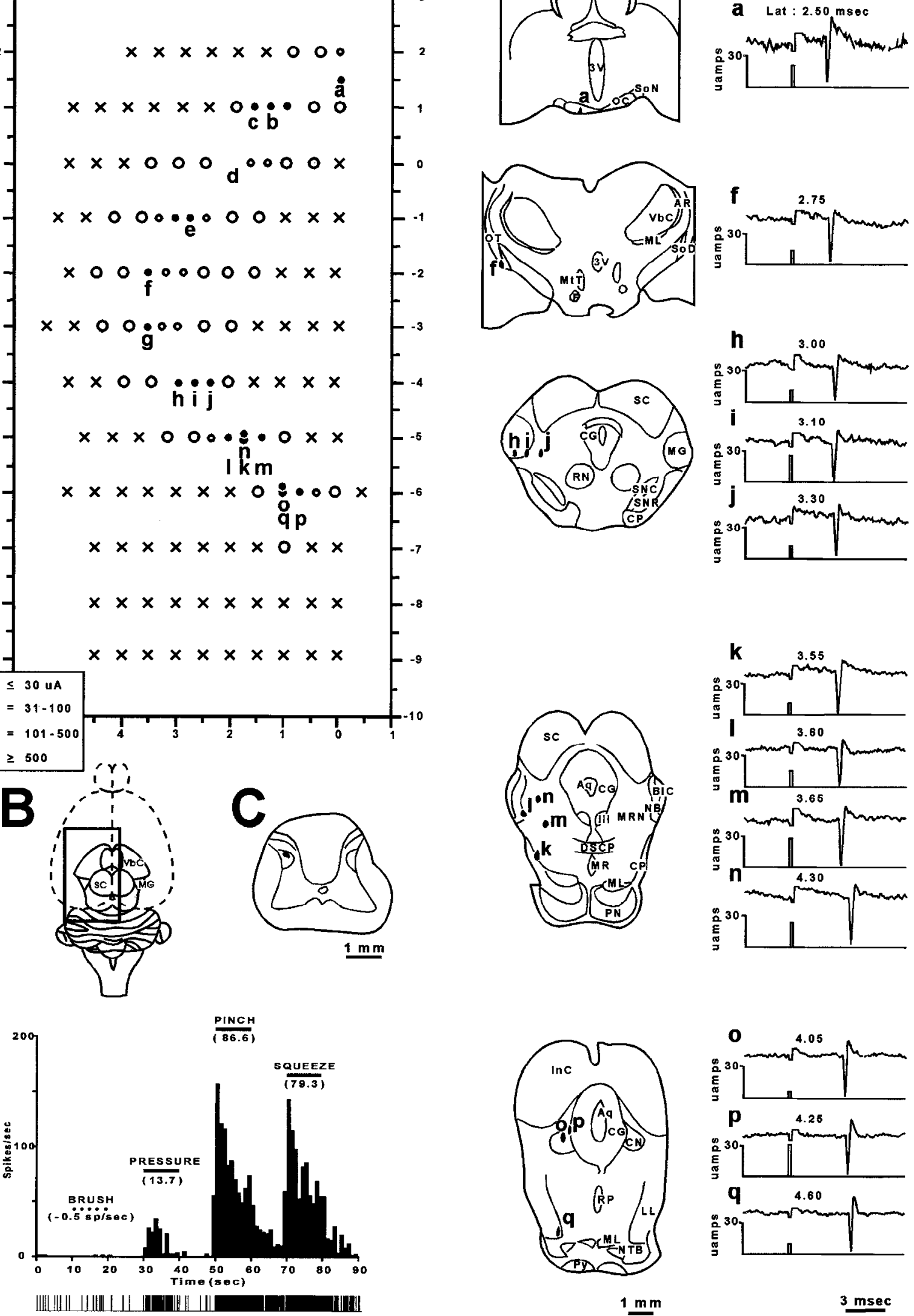

Figure 6. 
8402 Zhang et al. - Descending SHT Axons in the Ipsilateral Brain
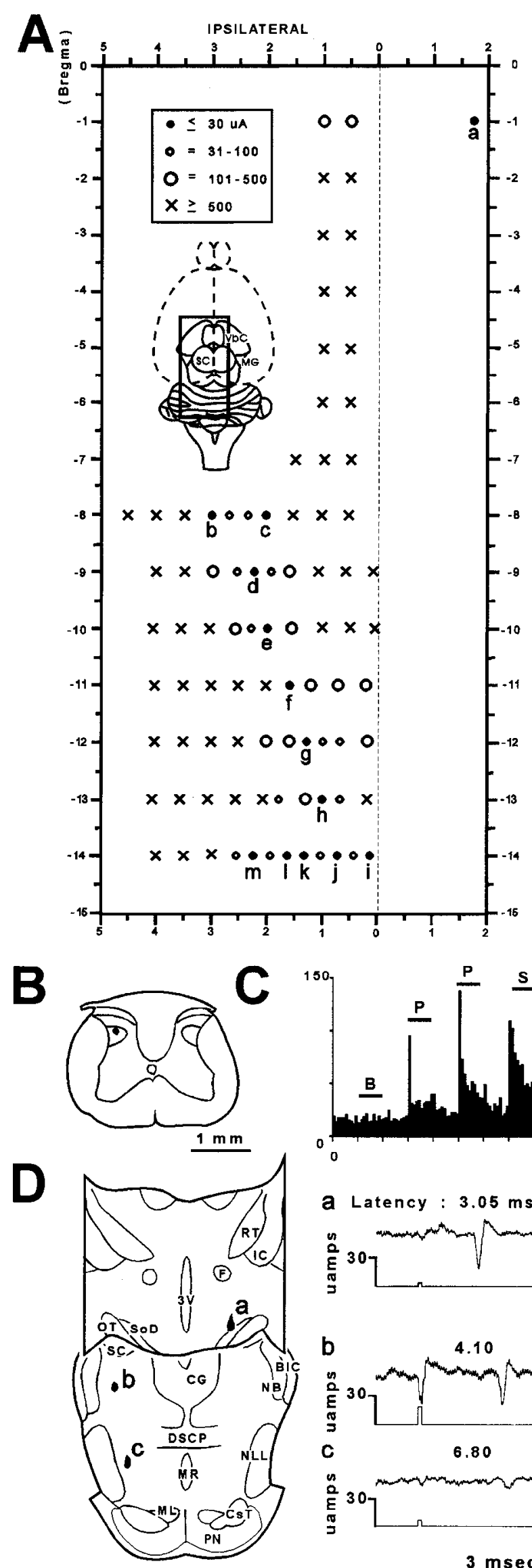
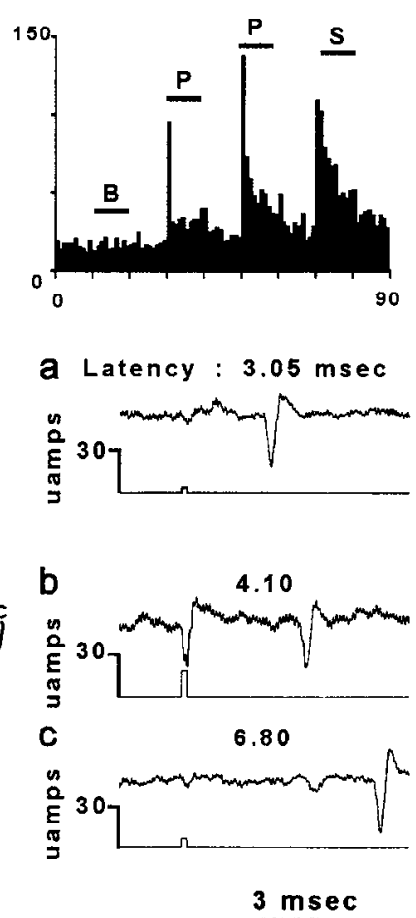
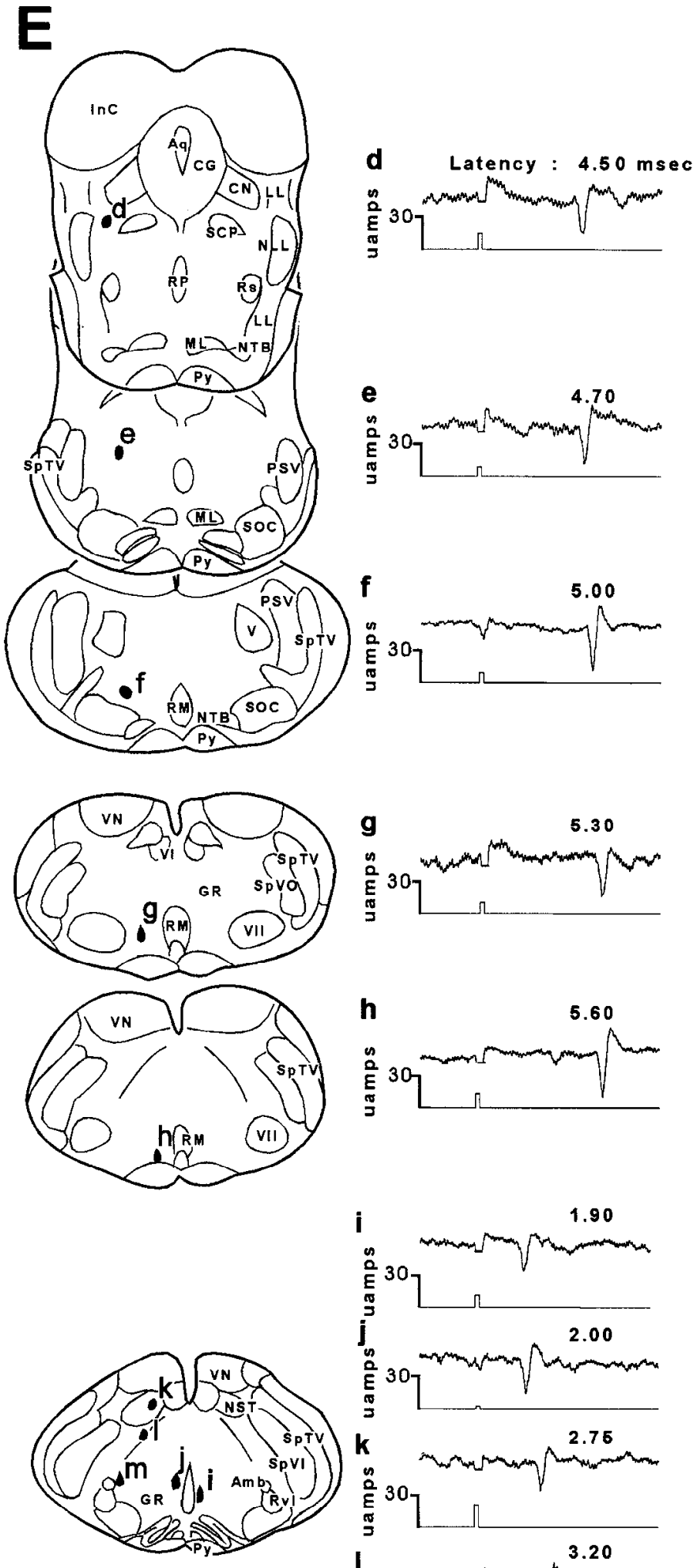

$1 \mathrm{~m} \mathrm{~m}$

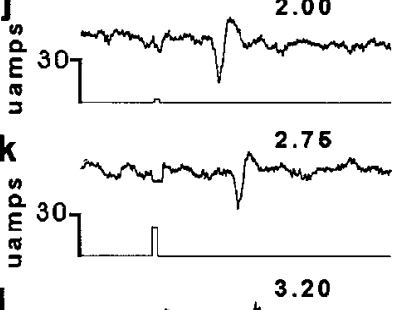

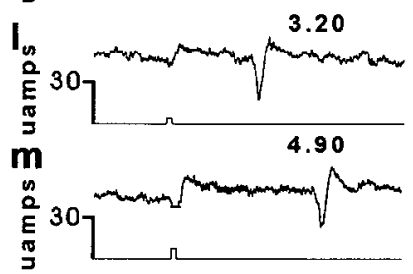

$3 \mathrm{msec}$

Figure 7. 
in the Figure $2 F$. All recording points for neurons with axons that terminated in $\mathrm{CN}$ were in the DDH. One of the two physiologically characterized neurons was classificd as a WDR ncuron, the other was an HT neuron.

Four of 14 descending SHT axons that were surrounded in the ipsilateral midbrain appeared to terminate in the nucleus of the brachium inferior colliculus (NB) (Fig. 4, -7.0, -7.8). A photomicrograph of a lesion at a surrounded low threshold point in the ipsilateral NB is shown in the Figure $2 G$. Recording sites for each of these were in the DDH. The one physiologically characterized neuron was classified as an HT neuron.

Ipsilateral pons and medulla. Seventeen low threshold points for antidromic activation of 11 SHT neurons were found in the ipsilateral pons. These low threshold points were located in the pontine reticular nucleus and in or near the superior olivary complex (Fig. 4, -7.8 through -9.7). Three SHT axons were followed posteriorly into the medulla. These were activated from five low threshold points in the ventral reticular formation (Fig. $4,-10.5$ through -12.0 ). None of the low threshold points in the pons or medulla could be surrounded posteriorly. The recording points for these 11 neurons were mainly in DDH (9). One was in SDH and another in $\mathrm{VH}$. Of 6 tested neurons, 3 were classified as WDR neurons and 3 as HT neurons.

Figure 7 illustrates an example of an SHT axon that appeared to project through the contralateral hypothalamus, cross the midline, then descend posteriorly to at least the level of the rostral ventromedial medulla. This neuron was initially activated antidromically from $\mathrm{a}$ in the contralateral SoD at a latency of 3.05 msec $(A, D)$. The neuron could also be activated antidromically from tracks in the ipsilateral hypothalamus, midbrain, pons, and medulla at progressively longer latencies (Fig. $7 A$ ). It could not be antidromically activated from tracks in the medial parts of the ipsilateral caudal hypothalamus, thalamus and midbrain using $500 \mu \mathrm{A}$ currents (Fig. 7A), suggesting that the axon did not cross the midline at these levels. One or two low threshold points (b-h) were found at each examined level from the caudal midbrain to the rostral medulla (Fig. 7A). Low threshold points were located in the mesencephalic reticular nucleus, pontine reticular nucleus, and the gigantocellular reticular nucleus of rostral medulla (Fig. $7 D, E$ ). Point $\mathrm{h}$ was in the rostral ventromedial medulla, just lateral to nucleus raphe magnus (Fig. $7 E$ ). The antidromic latency from this point was $5.6 \mathrm{msec}$ (Fig. $7 E$ ). In the plane $1 \mathrm{~mm}$ posterior to $\mathrm{h}$, five low threshold points $(\mathrm{i}-\mathrm{m})$ were found $(A, E)$. The antidromic latency at each of the five points was shorter than that at $\mathbf{h}$. Point $i$ was located in the contralateral medulla. The antidromic latency from $i$ was $1.9 \mathrm{msec}$. Point $j$ was located close to the midline on the ipsilateral side. The latency at $\mathrm{j}$ was $2.0 \mathrm{msec}$. The antidromic latencies of $\mathrm{k}-\mathrm{m}$ were longer than that at $j$ but shorter than that from $h$. Our interpretation of these findings is that a branch may have emanated from the parent axon in the contralateral medulla, crossed the midline, and terminated in several areas of the ipsilateral medulla. We did not observe any long latency responses in the areas in which short latency responses were found, a finding that probably resulted from the fact that antidromic action potentials elicited from the short latency points would undoubtedly ascend in the parent axon and collide with action potentials elicited in the ipsilateral descending axon. Therefore, it appears that the terminal area of this and similar SHT axons could not be determined using the present methods. This HT unit $(C)$ was recorded in the DDH in $\mathrm{C} 8(B)$. A photomicrograph of the lesion marking point $\mathrm{h}$ is shown in Figure $2 H$. In four cases (including two that were followed into the ipsilateral medulla), short latency low threshold points were encountered in the caudal brainstem.

In cight cascs in which SHT neurons were activated bilaterally from the brain (including two in which the neuron was activated in the ipsilateral pons and medulla), electrode penetrations were made across the entire mediolateral extend of the spinal cord at the segment $\mathrm{C} 1$. In each of these cases, a single low threshold point with a short latency was located in the contralateral white matter. None of the examined neurons could be activated from the low threshold points on the ipsilateral side of the cord, suggesting that none of the examined descending axons reached the spinal cord.

\section{Branches from descending SHT axons}

An example of activation of an apparent collateral branch from an SHT axon is illustrated in Figure 7. Two low threshold points $(\mathrm{b}, \mathrm{c})$ were found in one rostral-caudal level $(A, D)$. Point b was in the mesencephalic reticular nucleus and had a short antidromic latency. Point $\mathrm{c}$ was in the pontine reticular nucleus and was activated at a considerably longer latency $(D)$. The latency from c was longer than those from more posteriorly located points $(D, E)$. These findings are consistent with the idea that a slowly conducting daughter branch from the ipsilateral descending main axon projected to the pontine reticular nucleus.

Figure $2 D$ illustrates lesions in the ipsilateral thalamus at the sites of what appeared to be a parent axon and a terminating branch that originated from it. The neuron was activated from a point near the ventrolateral border of the medial geniculate at a latency of $2.85 \mathrm{msec}$ and from the posterior thalamic nucleus (Po) at a latency of $3.3 \mathrm{msec}$. The antidromic latency from the point in Po was longer than that from the low threshold point of next posterior level $(3.0 \mathrm{msec})$ and the neuron could not be activated with high currents in areas that were anterior, posterior, or medial to the point in Po. These findings suggest that a collateral branch left the parent axon laterally near the medial geniculate and terminated in or near Po.

Nine surrounded collateral branches from six SHT neurons were found in the ipsilateral thalamus. Four of these low threshold points were located in the medial part of the medial geniculate, three in the posterior thalamic nucleus, one in the optic tract and one in the ventrobasal complex (Fig. 4, -4.3 through

6.0 ). Evidence was found for three collateral branches from 3 SHT neurons in the ipsilateral midbrain. Two were in the superior colliculus, and one was in the mesencephalic reticular nucleus (Fig. 4, -6.0 through -7.8 ). Two collateral branches from 2 SHT neurons were found in the ipsilateral pontine reticular nucleus (Fig. 4, -7.8, -9.7).

\section{Conduction velocities}

The average antidromic latency from the initial low threshold points in the contralateral hypothalamus to the recording points in the cervical enlargement for 56 examined neurons was $2.9 \pm$ $0.1 \mathrm{msec}$ (mean $\pm \mathrm{SE}$ ), range, $1.7-7.5 \mathrm{msec}$. Assuming that the axons crossed in the spinal cord (Dado et al., 1994c) and then ascended in a straight path to the hypothalamus, the estimated mean conduction velocity of these axons was $16.7 \pm 0.56 \mathrm{~m} / \mathrm{sec}$ (mean \pm SE), range, 5.9-24.4 m/sec (Fig. 8A). The estimated mean conduction velocity between the most rostral low threshold points and the most caudal low threshold points in the ipsilateral brain for 40 examined SHT axons was $6.02 \pm 0.45$ $\mathrm{m} / \mathrm{sec}$ (mean $\pm \mathrm{SE}$ ), range, $1.1-13.2 \mathrm{~m} / \mathrm{sec}$ (Fig. $8 B$ ). The difference in the conduction velocities of SHT axons in the ipsi- 

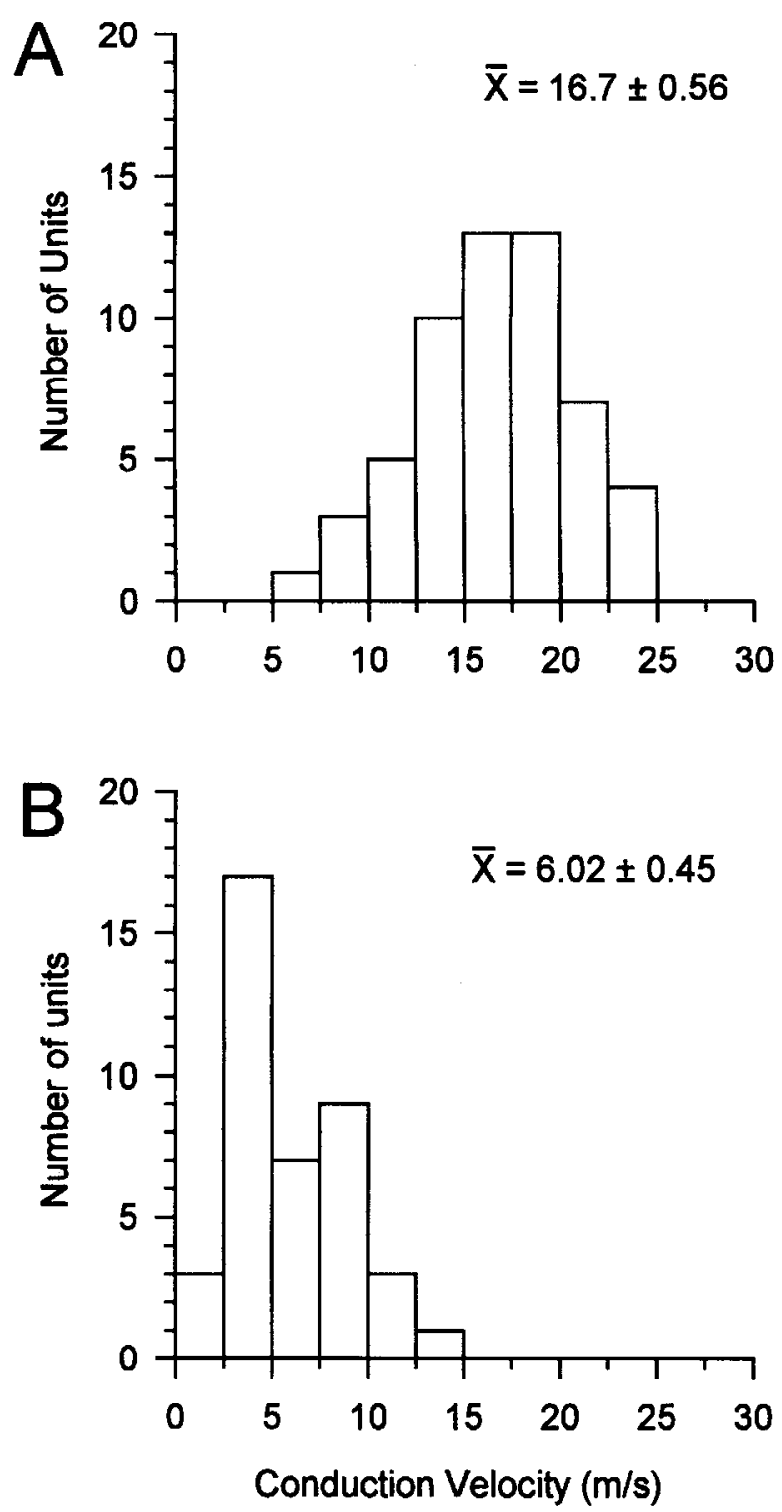

Figure 8. Histograms of conduction velocities of examined axons. A, Conduction velocities between the recording sites in the cervical enlargement and the low threshold points in the contralateral hypothalamus. $B$, Conduction velocities between the most rostral low threshold points and the most caudal low threshold points in the ipsilateral brain.

lateral and contralateral brain was significant $(P<0.0001, l$ test). Thus, the conduction velocities of SHT axons slowed considerably as they descended in the ipsilateral brain.

\section{Discussion}

The present findings indicate that the spinohypothalamic tract is far longer and more complex than envisioned in older (Chang and Ruch, 1949; Morin et al., 1951), or even in more recent anatomical and physiological studies (Burstein et al., 1987, 1990a, 1991; Katter et al., 1992; Dado et al., 1994a). It now appears that not only do SHT axons descend to the level of the posterior thalamus, they frequently continue to considerably more caudal levels. Almost half of the SHT axons that we were able to surround posteriorly with ineffective stimulating tracks were followed to at least the level of the midbrain. In addition, a sizable portion of SHT axons could be followed into the ip- silateral pons and even medulla. This ascending and descending projection is schematically depicted in Figure 9.

From the level of the posterior part of the optic chiasm to the level of the posterior pole of the ventrobasal complex, SHT axons appear to descend in a highly circumscribed projection. With the exception of the antidromic activation of two apparent axonal branches in the $\mathrm{VbC}$ and of another axon in the ventromedial hypothalamic nucleus, all 80 low threshold points from which examined SHT axons were activated were located within or closely adjacent to the SoD. These findings are consistent with several types of previous findings. Early anatomical studies indicated that lesions of the spinal cord white matter cause degeneration of a bundle of axons in contralateral SoD in monkeys and rats (Chang and Ruch, 1949; Morin et al., 1951; Minderhoud, 1967). Recent anterograde tracing studies have also described bundles of labeled axons in the SoD ipsilateral to the injection sites in the spinal cord gray matter in rats (Cliffer et al., 1991) and monkeys (Newman et al., 1995). In previous physiological studies, low threshold points for antidromic activation in the ipsilateral diencephalon were concentrated in the SoD (Burstein et al., 1991; Dado et al., 1994a). All low threshold points in the ipsilateral SoD in the previous and present studies had latencies that were longer than those for the same cells in the contralateral SoD, suggesting that each of the examined SHT axons initially coursed through the contralateral hypothalamus before reaching the ipsilateral SoD.

We (Burstein et al., 1991; Cliffer et al., 1991; Dado et al., 1994a) and others (Chang and Ruch, 1949; Morin et al., 1951; Newman et al., 1995) noted previously that within the diencephalon ascending SHT axons are also located in a compact bundle in the SoD. Thus, it appears that SHT axons ascend and descend within the diencephalon in locations that are mirror images of each other. It is interesting that SHT axons appear to ascend and descend in a compact bundle since this arrangement may make it possible to produce relatively selective lesions of this projection. Few, if any, other nociceptive pathways are located within such a restricted area of the CNS and at what appears to be a considerable distance from other nociceptive systems.

The fact that in a large number of experiments in different animals, virtually all low threshold points in the anterior diencephalon were located in a structure as small as the SoD suggests that the methods of antidromic activation that we used in this and previous studies can produce consistent results. The fact that the results are in such close accord with anatomical studies indicates that these methods produce results that are accurate also.

Fourteen percent of the SHT axons that could be surrounded with ineffective stimulating tracks appeared to terminate in the ipsilateral hypothalamus. The surrounded low threshold points were located mainly in SoD and optic tract. It is unclear why these axons seemed to terminate in what appears to be white matter. There are several possible explanations including (1) there may be previously unreported synapses in these areas, (2) branches may have left the axons at this point and our techniques were incapable of revealing them. It should be pointed out that in these studies pulses of a single duration $(200 \mu \mathrm{sec})$ were used. Longer pulses might have revealed greater numbers of axonal branches. Also, antidromic activation frequently provides evidence for far smaller numbers of axonal branches than does intra-axonal staining techniques (reviewed in Dado et al., 1994a). Studies using intra-axonal staining methods could add significantly to our understanding of the SHT and SoD.

Twenty-six percent of the SHT axons that we were able to 


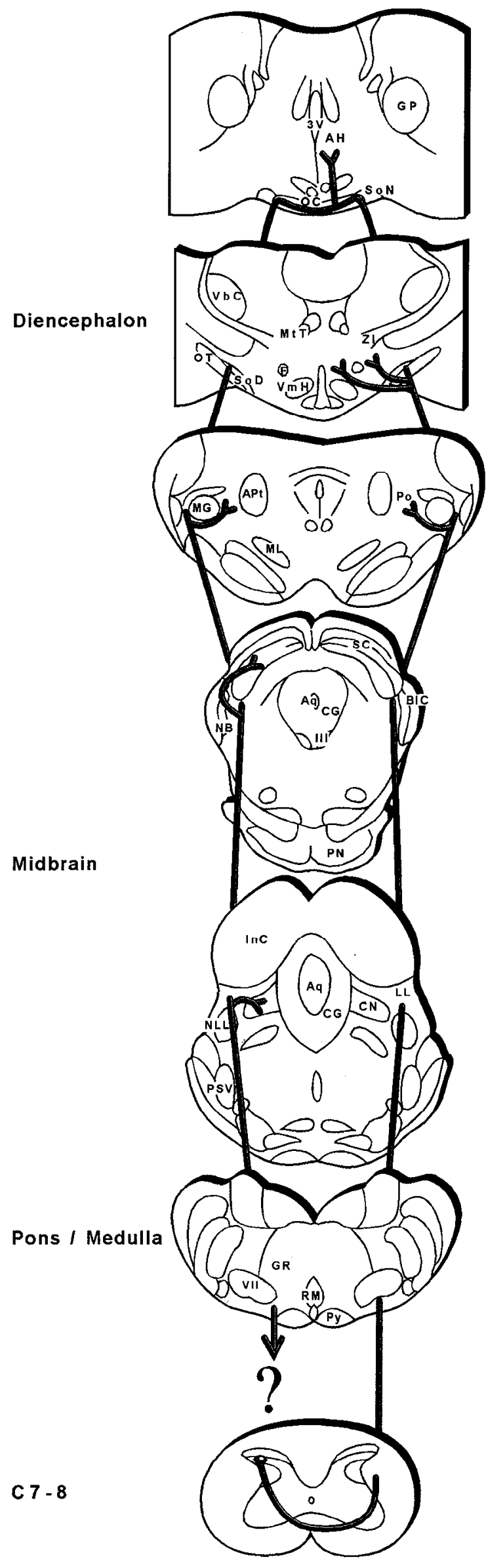

surround with ineffective stimulating tracks appeared to end in the ipsilateral thalamus including the $\mathrm{VbC}$ and the medial part of the medial geniculate nucleus. Three branches from SHT axons were also surrounded by ineffective stimulating tracks in $\mathrm{PO}$. Many nociceptive neurons in the $\mathrm{VbC}$ and $\mathrm{PO}$ in rats have bilateral receptive fields (Shigenaga et al., 1973; Guilbaud et al., 1980). It is possible that the complex bilateral projections described in the present study contribute to the formation of such receptive fields.

Forty percent of the SHT axons that were surrounded by ineffective stimulating tracks appeared to terminate in the midbrain. The most posterior low threshold points of 4 of these 14 axons were located in the intermediate or deep layers of the superior colliculus. Also, 2 of 3 surrounded branches in the ipsilateral midbrain ended in this area. Another axon appeared to cross the midline in the commissure of the superior colliculus and enter the contralateral superior colliculus. In addition, three SHT neurons were activated antidromically in the ipsilateral superior colliculus but, for technical reasons, we could not surround these points posteriorly. Taken together, these findings suggest that the superior colliculus is an important target of descending SHT axons. The cuneiform nucleus appears to be another major target for descending SHT axons. The most posterior surrounded low threshold points of 4 of 14 SHT axons were located in the cuneiform nucleus.

Several lines of evidence suggest that neurons in both the superior colliculus and the cuneiform nucleus can be activated by noxious stimulation of the ipsilateral body. Neurons in both areas have bilateral nociceptive receptive fields (Stein and Dixon, 1978; Hardy et al., 1983; Haws et al., 1989). Also, neurons in both areas bilaterally express c-fos in response to unilateral noxious mechanical or thermal stimulation of the hindpaw (Bullitt, 1990; Lanteri-Minet et al., 1994). In addition, unilateral noxious stimulation produces significantly increased 2-deoxyglucose uptake in both areas bilaterally (Porro et al., 1991; Mao et al., 1993). Anatomical experiments indicate that both areas receive bilateral projections from the spinal cord (Mehler et al., 1960; Antonetty and Webster, 1975; Zemlan et al., 1978; Menetrey et al., 1982; Swett et al., 1985; Bernard et al., 1995). The present findings suggest that descending SHT axons may be an important part of the ipsilateral projection from the spinal cord to these nuclei.

Five SHT axons were antidromically activated from the brachium of the superior colliculus (BSC) as they entered the superior colliculus (Fig. 5; Fig. 4, -6.0). The BSC is the primary path through which axons from the retina reach the superior colliculus. It appears, therefore, that SHT axons run is association with axons of the visual system for many millimeters, as they course through the hypothalamus in the SoD and as they enter the superior colliculus. This strongly parallel projection by the axons of these different sensory systems raises the possibility that these axons share similar underlying mechanisns of early axonal guidance.

Eleven SHT axons were followed posteriorly through the ipsilateral midbrain and into the ventral pons and three of these

\section{$\leftarrow$}

Figure 9. Schematic representation of the course of spinohypothalamic tract (SHT) axons. Note descending SHT axon at left. The question mark indicates that the area(s) of terminate of SHT axons in the medulla is not known. Findings supporting the description of SHT axons and their branches in the contralateral diencephalon are reviewed in Giesler et al. (1994). See Appendix for abbreviations. 
were followed into the ipsilateral rostral medulla. Low threshold points in the medulla were located in the ventral reticular formation, lateral to the nucleus raphe magnus and dorsal to the pyramidal tract. The areas of apparent termination could not be detcrmincd for any of the axons that descended to the pons or medulla. In several cases, electrical stimulation in these areas resulted in antidromic activation of the examined SHT neuron at multiple short latencies. These short latency responses appeared to indicate that ascending SHT axons in the contralateral brainstem gave off collateral branches that crossed the midline in the medulla (see Results). In a recent study of ascending SHT axons using the same methods of antidromic activation, we (Kostarczyk et al., 1995) have seen additional evidence for the presence of many branches from SHT axons in the medulla. Therefore, although it is clear that some descending SHT axons reach the level of the pons and rostral medulla, the area in which they terminate remains unknown. In several cases in this study and on many occasions in a previous study (Dado et la., 1994c), we stimulated across the medial-lateral extent of the upper cervical spinal cord. In no case was a long latency antidromic response produced by stimulating in the ipsilateral cord. Thus, it seems likely that these descending SHT axons did not reach the spinal cord and must have terminated within the medulla.

Descending SHT axons were located in the reticular formation of the ventral and rostral medulla. The reticular formation is importantly involved in producing arousal. Nociceptive stimulation strongly arouses sleeping animals and causes cortical desynchronization (Magoun, 1963). It is possible that part of the nociceptive information that reaches the reticular formation may be carried by descending SHT axons. Similarly, the reticular formation and raphe nuclei of the rostral medulla also are thought to be part of an antinociceptive system (Basbaum and Fields, 1984) and the SHT may provide nociceptive input to this system.

In several cases, descending SHT axons could be followed to points in the pons and medulla that were $15-18 \mathrm{~mm}$ caudal to where they crossed into the ipsilateral hypothalamus. Therefore, these axons ascended to the contralateral hypothalamus, decussated in the posterior optic chiasm and then turned posteriorly and descended to reach the lower brainstem, spanning a total distance of more than $30 \mathrm{~mm}$. The low threshold points in the ipsilateral medulla are only 2-3 $\mathrm{mm}$ away from the area in which SHT axons ascend in the contralateral medulla (Kostarczyk et al., 1995). It is unclear why some SIIT axons travel through this long complex path to reach the ipsilateral pons and medulla when this area apparently also receives projections from collateral branches of ascending SHT axons that cross the midline in the brainstem.

It is likely that large numbers of SHT neurons issue axons that project through this lengthy complex projection. Injections of Fluoro-Gold into one side of the rat hypothalamus labeled as many as 5400 neurons in the contralateral spinal cord (Burstein et al, 1990a). In this and also in another recent study of SHT neurons in the cervical enlargement (Dado et al., 1994a), we found that roughly $85 \%$ of the examined axons that reached the contralateral hypothalamus decussated in the posterior optic chiasm. In a study of SHT neurons in the lumbar enlargement, we (Burstein et al., 1991) also noted that a high percentage of examined SHT axons decussate in the SoD. Recent anatomical findings also indicate that a large percentage of SHT axons reach the ipsilateral hypothalamus by crossing in the SoD. Burstein et al. (personal communication) have found that lesions of the SoD on the midline can prevent the retrograde labeling of virtually all neurons in the ipsilateral spinal cord. The numbers of labeled SHT neurons in the contralateral spinal cord is not affected by these lesions. Therefore, it appears that comparably high percentages of SIIT neurons at all levels of the cord have axons that decussate in the SoD. It also appears that several thousand SHT axons cross the midline in each direction within the posterior optic chiasm.

Nociceptive responses are complex and often include affective, neuroendocrine and autonomic components (for review, see Willis, 1985; Giesler et al., 1994). Noxious stimuli can also produce arousal and activate antinociceptive descending inhibitory systems (Basbaum and Fields, 1984). These complex responses to noxious stimuli involve large numbers of areas in the brain and, undoubtedly as a result, information about painful stimuli is transmitted widely throughout the brain (Bullitt, 1990; Porro et al., 1991; Mao et al., 1993; Lanteri-Minet et al., 1994). The present findings indicate that the spinohypothalamic tract appears to be capable of carrying nociceptive information bilaterally to many areas in the diencephalon and brainstem that are involved in the production of multifaceted responses to noxious stimuli.

\section{Appendix}

\section{Abbreviations}

$\mathrm{AH} \quad$ anterior hypothalamus area

Amb ambiguus nucleus

APt anterior pretectal nucleus

$\mathrm{Aq}$ aqueduct

AR acoustic radiation

Arc arcuate hypothalamic nucleus

BIC brachium inferior colliculus

BSC brachium superior colliculus

CG central gray

$\mathrm{CN} \quad$ cuneiform nucleus

CP cerebral peduncle

C'T corticospinal tract

DDH deep dorsal horn

DLG dorsal lateral geniculate nucleus

$\mathrm{DmH}$ dorsomedial hypothalamic nucleus

DSCP decussation of the superior cerebellar peduncle

$F$ fornix

FR fasciculus retroflexus

GP globus pallidus

GR gigantocellular reticular nucleus

$\mathrm{Hb}$ habenular nucleus

IC internal capsule

III oculomotor nucleus

InC inferior colliculus

IO inferior olive

LL lateral lemniscus

LP lateral posterior thalamic nucleus

LPg lateral paragigantocellular nucleus

$\mathrm{MG}$

ML

MR

MRN

$\mathrm{MtT}$

NB

NLL

NST

NTB

$\mathrm{OC}$

OT

PcR

PN

Po

PRN

PSV

PvN medial geniculate nucleus

medial lemniscus

median raphe nucleus

mesencephalic reticular nucleus

mammillothalamic tract

nucleus brachium inferior colliculus

nucleus of the lateral lemniscus

nucleus of the solitary tract

nucleus of the trapezoid body

optic chiasm

optic tract

parvocellular reticular nucleus

pontine nucleus

posterior thalamic nucleus

pontine reticular nucleus

principal sensory nucleus of the trigeminal nerve

paraventricular hypothalamic nucleus 


$\begin{array}{ll}\text { Py } & \text { pyramidal tract } \\ \text { RN } & \text { red nucleus } \\ \text { RM } & \text { nucleus raphe magnus } \\ \text { RO } & \text { nucleus raphe obscurus } \\ \text { RP } & \text { nucleus raphe pontis } \\ \text { Rs } & \text { rubrospinal tract } \\ \text { RT } & \text { reticular thalamic nucleus } \\ \text { Rvl } & \text { rostroventrolateral reticular nucleus } \\ \text { SC } & \text { superior colliculus } \\ \text { Sch } & \text { suprachiasmatic nucleus } \\ \text { SCP } & \text { superior cerebellar peduncle } \\ \text { SDH } & \text { superficial dorsal horn } \\ \text { SNC } & \text { substantia nigra, compact part } \\ \text { SNR } & \text { substantia nigra, reticular part } \\ \text { SOC } & \text { superior olivary complex } \\ \text { SoD } & \text { supraoptic decussation } \\ \text { SoN } & \text { supraoptic hypothalamic nucleus } \\ \text { SpTV } & \text { spinal tract of the trigeminal nerve } \\ \text { SpVI } & \text { spinal nucleus of the trigeminal, interpolar part } \\ \text { SpVO } & \text { spinal nucleus of the trigeminal, oral part } \\ \text { V } & \text { motor nucleus of the trigeminal nerve } \\ \text { VI } & \text { abducens nucleus } \\ \text { VII } & \text { facial nucleus } \\ \text { VbC } & \text { ventrobasal complex } \\ \text { VmH } & \text { ventromedial hypothalamic nucleus } \\ \text { VN } & \text { vestibular nucleus } \\ \text { ZI } & \text { zona incerta } \\ \text { 3V } & \text { third ventricle }\end{array}$

\section{References}

Antonetty CM, Webster KE (1975) The organization of the spinotectal projection. An experimental study in the rat. J Comp Neurol 163: $449-466$.

Basbaum AI, Fields HL (1984) Endogenous pain control systems: Brainstem spinal pathways and endogenous circuitry. Annu Rev Neurosei 7:309-338.

Bernard JF, Dallel R, Raboisson P, Villanueva L, Bars DL (1995) Organization of the efferent projections from the spinal cervical enlargement to the parabrachial area and periaqueductal gray: a PHA-L study in the rat. $\mathbf{J}$ comp Neurol 353:480-505.

Bester H, Menendez L, Besson JM, Bernard JF (1995) Spino(trigemino)parabrachiohypothalamic pathway: electrophysiological evidence for an involvement in pain processes. J Neurophysiol 73: $568-585$.

Bullitt E (1990) Expression of C-fos-like protein as a marker for neuronal activity following noxious stimulation in the rat. J Comp Neurol 296:517-530

Burstein R, Cliffer KD, Giesler GJ Jr (1987) Direct somatosensory projections from the spinal cord to the hypothalamus and telencephalon. J Neurosci 7:4159 4164.

Burstein R, Cliffer KD, Giesler GJ Jr (1990a) Cells of origin of the spinohypothalamic tract in the rat. J Comp Neurol 291:329-344.

Burstein R, Dado RJ, Giesler GJ Ji (1990b) The cells of origin of the spinothalamic tract of the rat: a quantitative reexamination. Brain Res 511:329-337.

Burstein R, Dado RJ, Cliffer KD, Giesler GJ Jr (1991) Physiological characterization of spinohypothalamic tract neurons in the lumbar enlargement of rats. J Neurophysiol 66:261-284.

Carstens E, Leah J, Lechner J, Zimmerman M (1990) Demonstration of extensive brainstem projections to medial and lateral thalamus and hypothalamus in the rat. Neuroscience 35:609-626.

Chang H-T, Ruch TC (1949) Spinal origin of the ventral supraoptic decussation (Gudden's commissure) in the spider monkey. J Anat 83: $1-9$.

Cliffer KD, Burstein R, Giesler GJ Jr (1991) Distributions of spin othalamic, spinohypothalamic and spinotelencephalic fibers revealed by anterograde transport of PHA-L in rats. J Neurosci 11:852-868.

Dado RJ, Katter JT, Giesler GJ Jr (1994a) Spinothalamic and spinohypothalamic tract neurons in the cervical enlargement of rats. I. Locations of antidromically identified axons in the thalamus and hypothalamus. J Neurophysiol 71:959-980.

Dado RJ, Katter JT, Giesler GJ Jr (1994b) Spinothalamic and spinohypothalamic tract neurons in the cervical enlargement of rats. II.
Responses to innocuous and noxious mechanical and thermal stimuli. J Neurophysiol 71:981-1002.

Dado RI, Katter IT, Giesler GJ Jr (1994c) Spinothalamic and spinohypothalamic tract neurons in the cervical enlargement of rats. III. Locations of antidromically identified axons in the cervical cord white matter. J Neurophysiol 71:1003-1021.

Giesler GJ Jr, Katter JT, Dado RJ (1994) Direct spinal pathways to the limbic system for nociceptive information. Trends Neurosci 17:244 250.

Guilbaud G, Peschanski M, Gautron M, Binder D (1980) Neurones responding to noxious stimulation in VB complex and caudal adjacent regions in the thalamus of the rat. Pain 8:303-318.

Hardy SGP, Haigler HJ, Leichnetz GR (1983) Paralemniscal reticular formation: response of cells to a noxious stimulus. Brain Res 267: 217-223.

Haws CM, Williamson AM, Fields HL (1989) Putative nociceptive modulatory neurons in the dorsolateral pontomesencephalic reticular formation. Brain Res 483:272-282.

Janig W (1990) The sympathetic nervous system in pain: physiology and pathophysiology. In: Pain and the sympathetic nervous system (Stanton-Hicks M, ed), pp 17-89. Boston: Kluver.

Katter JT, Dado RJ, Giesler GJ Jr (1992) Response properties and locations of axons of lumbosacral spinothalamic (STT) and spinohypothalamic (SHT) tract neurons in rats. Soc Neurosci Abstr 18:.

Kostarczyk E, Zhang X, Giesler GJ Jr (1995) Spinohypothalamic tract (SH'T) neurons in the cervical enlargement of rats: location of antidromically identified axons in the contralateral brains. Soc Neurosci Abstr 21:1166.

Lanteri-Minet M, Weil-Fugazza J, DePommery J, Menetrey D (1994) Hindbrain structures involved in pain processing as revealed by the expression of C-fos and other immediate early gene proteins. Neuroscience 58:287-298

Magoun HW (1963) The waking brain, 2nd ed. Springfield: Thomas.

Mao J, Mayer DJ, Price DD (1993) Patterns of increased brain activity indicative of pain in a rat model of peripheral mononeuropathy. $J$ Neurosei 13:2689-2702.

Mehler WR, Feferman ME, Nauta WJH (1960) Asceding axon degeneration following anterolateral cordotomy. An experimental study in the monkey. Brain 83:718-750.

Menetrey D, DePommery J (1991) Origins of spinal ascending pathways that reach central areas involved in visceroception and visceronociception in the rat. Eur J Neurosci 3:249-259.

Menetrey D, Chaouch A, Binder D, Besson JM (1982) Origin of the spinomesencephalic in the rat: an anatomical study using the retrograde transport of horseradish peroxidase. J Comp Neurol 206:193207.

Minderhoud JM (1967) Observations on the supra-optic decussations in the albino rat. J Comp Neurol 129:297-312.

Morin F, Schwartz HG, O'Leary JL (1951) Experimental study of the spinothalamic and related tracts. Acta Psychiat Neurol 26:371-396.

Newman HM, Stevens RT, Apkarian AV (1995) Direct spinal projections to limbic and striatal areas: anterograde transport studies from upper cervical spinal cord and the cervical enlargement in squirrel monkey and rat. J Comp Neurol, in press.

Paxinos G, Watson C (1986) The rat brain in stereotaxic coordinates. New York: Academic.

Porro CA, Cavazzuti M, Galetti A, Sassatelli L (1991) Functional activity mapping of the rat brainstem during formalin-induced noxious stimulation. Neuroscience 41:667-680.

Ranck JB (1975) Which elements are excited in electrical stimulation of mammalian central nervous system: a review. Brain Res 98:417440 .

Shigena Y, Matano S, Okada K, Sakai A (1973) The effects of tooth pulp stimulation in the thalamus and hypothalamus of the rat. Brain Res 63:402-407.

Stein BE, Dixon JP (1978) Superior colliculus neurons respond to noxious stimuli. Brain Res 158:65-73.

Swett JE, McMahon SB, Wall PD (1985) Long ascending projections to the midbrain from cells of lamina I and nucleus of the dorsolateral funiculus of the rat spinal cord. J Comp Neurol 238:401-416.

Willis WD Jr (1985) The pain system. Basel: Karger.

Zemlan FP, Leonard C, Kow L-M, Pfaff DW (1978) Ascending tracts of the lateral columns of the rat spinal cord: a study using the silver impregnation and HRP technique. Exp Neurol 62:298-334. 